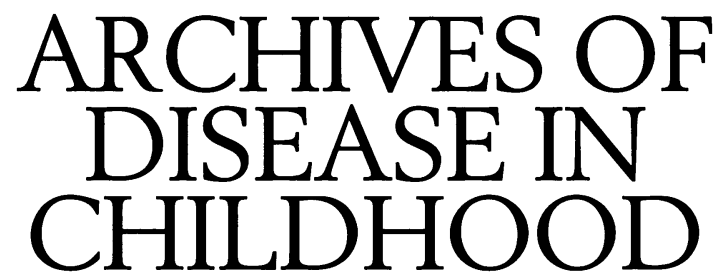

The Fournal of the Royal College of Paediatrics and Child Health

\title{
Annotations
}

\section{Future prospects for evidence-based child health}

How will the evidence-based health care movement be seen in the future? A passing fad as clinicians again embrace the 'art of medicine'? Enthusiastically adopted and institutionalised with central directives determining clinical decisions? Or, as the hyperbole fades, will it become viewed as just one of the essential tools that clinicians use in their day to day decisions?

\section{A passing fad?}

Is evidence-based health care just a passing fad, promoted by managers and purchasers enjoying their influence over clinical practice, but doomed to fail as a far too cumbersome method for dealing with the complexity and imprecision of real life clinical decisions? Critics argue that the emphasis which evidence-based health care gives to experimental evidence devalues important immeasurable factors ${ }^{1}$ (the 'art of medicine') and ignores the importance of caring and supportive clinicians who constitute much of what the health service has to offer. ${ }^{2}$

Few would argue against a humane health care system that treats people as individuals rather than a risk category. However, such a system needs to meet patients' expectations and rights to be fully informed about their clinical care, even if they decline to participate in decisions. Moreover, there may be a therapeutic benefit in their knowing what to expect. ${ }^{3}$ Most importantly, patients want clinicians who know (rather than believe) whether a treatment will work or not. And if we don't expose the evidence on which decisions are based, we might get it wrong, both by failing to maximise benefits for patients (and society) and failing to highlight the inadequacies of existing research.

Clinicians working in maternal and child health are only too well aware of examples where we have got it wrong: the 20 year delay from the first randomised controlled trial to the routine use of antenatal steroids for women in preterm labour, which substantially reduce the risk of neonatal death $^{4}$; the advice given by health professionals over two decades to put babies to sleep prone that increased, rather than reduced the risk of cot death ${ }^{5}$; and the 25 year delay in adequate evaluation of sight saving treatment for retinopathy of prematurity. ${ }^{6}$

\section{Overtaken by directives?}

What is the most efficient way of making sure that we don't get it wrong? If the evidence is available, surely what is needed is for someone to evaluate and summarise it in plain English and use the results to direct clinical decisions in whatever ways have been demonstrated (in randomised controlled trials (RCTs)) to most effectively change clinicians' behaviour? Fortunately, there is a growing research literature on the effectiveness of interventions in changing clinical practice. Methods for directing or reminding clinicians top a heterogeneous list which includes: computer reminders, patient mediated interventions (for example educational material or reminders), opinion leaders, academic detailing (like pharmaceutical company representatives), audit and feedback and guidelines with rigorous evaluation. ${ }^{7-9}$ Conferences have been found to be ineffective in this league table of interventions to change specific practices.

Should more clinical decisions be determined by directive approaches? Where the decision is straightforward (for example whether or not to give antenatal steroids), the evidence on which it should be based is incontrovertible, the balance of harm and benefit clearly established, ${ }^{10}$ and clinicians are still not offering interventions of proved benefit, then directive methods are likely to be most appropriate. Guidelines are a widely used method but are most credible if they are explicit about the evidence on which they are based ${ }^{11}$ and about the values attributed to the various outcomes. ${ }^{10}$ Greater consistency in guideline recommendations ${ }^{12}$ and the specification of absolute risk differences for different patient groups would increase their usefulness. Purchasers and managers can play a major part in determining the quality of service by promoting and monitoring implementation of such interventions, and by devising imaginative strategies that take account of social influences and keep clinicians receptive to this 'top down' approach. ${ }^{13}$ One way may be to extend their role. For example, guidelines for the screening and treatment of retinopathy of prematurity were launched in conjunction with a nationwide programme of training, audit, and research. ${ }^{14}$

\section{Uncertain evidence}

What are the other clinical decisions that are common, clinically important or of high cost, which meet the criteria 
of being based on incontrovertible evidence and are not already practised on a sufficiently wide scale?

The main problem is that incontrovertible evidence is rare. In reality, most clinical and policy decisions are based on evidence of varying degrees of uncertainty. ${ }^{15} \mathrm{~W}$ ill there be more incontrovertible evidence in the future or will increasing knowledge lead to greater uncertainty? The latter seems more likely. The more we know about options for intervention and about the potential for benefiting or harming patients, or for increasing or reducing costs, the more complex are the decisions about who could or should benefit. In addition, as the pace of change of knowledge and technology accelerates, less of our practice will be based on 20 years worth of controlled trials, as the interventions evaluated are replaced by new developments.

The second problem is that sometimes, neither research (systematic reviews included) nor guidelines are able to address the questions that patients and clinicians really need to answer in order to make clinical decisions. For example, an excellent overview on the treatment of persistent glue ear in children recommended adoption of a 'watch and wait' policy instead of grommet insertion. ${ }^{16}$ Three RCTs, based on children with bilateral glue ear who had grommets inserted in one ear with the other ear acting as a comparison, were particularly informative to this recommendation. The studies showed that improvement in hearing deficit was less than 12 decibels at six months and less than 6 decibels at 12 months after grommet insertion. However, the authors highlighted important gaps in evidence. For purchasers, information was lacking on the costs of a watch and wait policy compared with surgery. For parents and clinicians, the effects on language development and behavioural outcomes were not known.

What does evidence-based health care have to offer? If the evidence underpinning most clinical decisions is so uncertain, does evidence-based health care have anything to offer clinicians? We believe it does. Firstly, it starts with the clinical problems faced by patients and clinicians and the decisions to be made rather than starting with the existing evidence researchers have chosen to generate. Inevitably this means that, for some questions, the evidence may be far from adequate, but will nevertheless be the best available on which clinicians and patients are able to base their decisions.

Secondly, evidence-based health care provides a way of breaking down complex decisions into their component parts, so that the evidence for the predicted outcome of a diagnostic test, treatment, or exposure can be examined separately from value judgments about what outcomes are preferred-whether for reasons of individual preference (patient or clinician), costs, or service pragmatism. Scientific evidence thereby informs decisions that are finally determined by clinicians, patient, clinical team, purchasers or management, whose value judgments are mostly made intuitively, but can be measured more formally. ${ }^{17} 18$

Thirdly, evidence-based health care emphasises the need to base decisions on evidence which shows what actually happens to patients rather than draw conclusions by extrapolation from observations at a molecular, cellular, or organ level.

Evidence-based health care has been defined as the 'conscientious, explicit and judicious use of current best evidence in making decisions about the care of individual patients'. ${ }^{19}$ It can be summarised as a decision making process that involves five steps:

(1) Framing answerable questions from clinical or policy problems

(2) Searching for the evidence (whether from research, clinical observation, or one's own practice)
(3) Appraising the evidence for its validity (closeness to the truth) and usefulness (relevance to the patient problem)

(4) Pending how to implement the findings of this search and appraisal into practice

(5) Evaluating the change in practice.

\section{An example}

Here is an example of how evidence-based health care can work in practice: suppose you are confronted with a 3 year old child with mild croup in the accident department at 10 $\mathrm{pm}$. The decision seems to be whether to admit or send the child home, but you think of another option, and a question. Answerable questions are best structured in three parts: the patient population, the intervention or exposure and, where relevant, a comparison group, and the most relevant outcome. Your question is: 'In children with mild croup seen in the emergency department.... (the patient population), ...does one dose of nebulised budesonide compared with no treatment... (the intervention and comparison group)....reduce the chance of admission to hospital? (the clinical outcome)'.

Use of a simple decision tree to map out the decision may prompt consideration of other questions. For example: 'in patients with mild croup does oral dexamethasone compared with nebulised budesonide reduce the chance of admission to hospital?' A further advantage of a decision tree is that, as absolute risks have to be allocated to the outcomes (for example chance of being admitted is $26 \%$ with placebo and $4 \%$ with nebulised budesonide ${ }^{20}$ ), this can sometimes make the balance of costs and benefits immediately obvious. A disadvantage is that decision trees can become complicated.

Spending time getting the question right is worthwhile as it guides the next steps. ${ }^{21}$ As this is a question about an intervention, first choice would be to look for a RCT, for example, using Medline. Having entered in croup, budesonide and 'clinical trial in pt', you can scan the abstracts to pick out those which refer to a similar population-those with mild to moderate croup, with hospital admission as an outcome. To help with the third step, appraisal of the evidence, excellent, readable guides have been generated by the Evidence-Based Medicine Working Group at McMaster University. ${ }^{22-29}$

Such a Medline search on the question of budesonide compared with placebo generated three studies, one of which involved children with mild to moderate croup and recorded hospital admission as an outcome. ${ }^{20}$ Fifty four children were given either nebulised budesonide or nebulised saline. A quick check on the validity confirmed that clinicians were blind to randomisation, follow up was complete in both groups, an intention to treat analysis was carried out, clinicians and patients were blind to treatment, and the groups were similar at the start of the trial. The reduction in the risk of admission was $22 \%$ (one admission prevented for every 4.5 children treated: $95 \%$ confidence interval 2.5 to 25 ). These findings were supported by a greater reduction in the croup severity score in treated children. Two other RCTs demonstrated a benefit of nebulised budesonide over placebo for moderate to severe croup, ${ }^{3031}$ and one of these showed similar outcomes for children treated with oral dexamethasone or nebulised budesonide. $^{31}$

This evidence is far from certain but is the best available at $10 \mathrm{pm}$ in the accident department. So how certain do you need to be? Clinicians need to be cautious about adopting findings from just three studies (as the results may have occurred by chance or be biased), and some clinicians (sometimes referred to as laggards ${ }^{32}$ ) may decide to wait for further evidence. Others may decide that the risks 
of adverse outcomes are low, that there is supportive evidence of the benefit of steroids in severe croup, including a meta-analysis of trials, ${ }^{33}$ and that overall benefits outweigh costs. There is no right or wrong decision and health care is probably best served by a mix of reflective 'innovative' and 'laggardly' clinicians. ${ }^{34}$

If this sounds like dodging the issue, consider the possible advantages of this exercise. The clinician has questioned standard practice and checked up on whether more effective treatment exists; the potential benefits of treatment and uncertainty of the evidence have been made explicit for the parents and clinicians involved; and lastly, members of the team can scrutinise whether this is the best available evidence and highlight the need for further information. For example: review policy when further RCTs are reported, particularly comparing oral dexamethasone with nebulised budesonide; search out the evidence on the risk of adverse effects of nebulised budesonide.

\section{Getting evidence-based health care into the system}

Undoubtedly, evidence-based health care is a daunting task for busy clinicians and managers to undertake for all the decisions they make. Organisations need to look at ways in which clinicians can be helped to help each other admit their lack of certainty, prompt and address questions about the evidence underpinning practice, and to support implementation and evaluation of practice. Fragmented work patterns and devolution of care works against such interchange and further reduces the opportunities for clinicians to have feedback about the outcome of their decisions..$^{35}$ One approach is to harness existing practice evaluation and continuing education sessions more fruitfully (for example journal clubs, grand rounds) so that common, important decisions are reviewed, and the evidence underpinning them evaluated in a systematic way. Such clinical evaluation could draw much more on service evaluation (audit, outcomes measurement, budget monitoring) to generate questions, provide information about local practice and support evaluation of implementation. Together, continuing education and practice and service evaluation activities could contribute much more to effective health care than their separate parts.

Developments in information technology and the published literature can make evidence-based health care easier and offer some short cuts. Access to on-line search facilities at the work site is available to a growing number of clinicians and managers and developments in the use of search filters can help make searching more efficient. ${ }^{36-39}$ Others may have already appraised the evidence. ${ }^{40}$ For example, secondary publications of research articles in the ACP fournal Club and Evidence-Based Medicine, publish summaries of articles that meet certain quality standards. The Cochrane Collaboration and York Centre for Reviews and Dissemination have set high standards for overviews and stimulated rapid growth in the number of overviews of research (now available on disk or CD-ROM ${ }^{4}$ ).

\section{Conclusion}

How will evidence-based health care be seen in the future? For those who hoped it would provide gold standard answers, our view may be unsettling. However, incontrovertible evidence is rare, and clinical decisions complex, which is why clinical care is provided by clinicians not technicians. Evidence-based health care cannot change this but may become a useful tool to help individual clinicians weigh up the evidence for themselves so that they can share the information with patients and incorporate patients' values and preferences in their clinical judgment. Exposition of the evidence underpinning clinical practice may also facilitate informed participation by non-clinicians in decisions about rationing. Finally, evidence-based health care provides a way for clinicians to articulate their priorities for research and thereby contribute to setting a research agenda which is more relevant to service needs.

Does evidence-based health care really help clinicians provide more effective health care? The evidence is uncertain, ${ }^{41}{ }^{42}$ but no doubt, more studies will be published over the next few years. However, given the complexity of clinical practice, one intervention is unlikely to be effective on its own. Evidence-based health care is one component of an evaluative culture to which developments in information technology, research-particularly the generation of overviews - and organisational factors also contribute.

RUTH GILBERT STUART LOGAN

Centre for Evidence-Based Child Health, Department of Epidemiology and Statistics, Institute of Child Health,

30 Guilford Street,

London WC1N 1EH

The Centre for Evidence-Based Child Health receives financial support from Great Ormond Street Hospital for Children NHS Trust and North Thames Regional $R$ and $D$ Directorate.

1 Polychronis A, Miles A, Bentley P. Evidence-based medicine: Reference? Dogma? Neologism? New Orthodoxy? fournal of Evaluation of Clinical Practice 1996;2:1-3.

Tudor Hart J, Dieppe P. Caring effects. Lancet 1996;347:1606-8

3 Kee F. Patients' prerogatives and perceptions of benefit. $B M \mathscr{F}$ 1996;312 958-60

4 Crowley P. Corticosteroids prior to preterm delivery. In: Neilson JP Crowther CA, Hodnett ED, Hofmeyr GJ, Keirse MJNC, Renfrew MJ, eds Pregnancy and childbirth module of the Cochrane database of systematic reviews. Updated 06 June 1996.) Available in the Cochrane Library (database on disk and CDROM). The Cochrane Collaboration; Issue 2. Oxford: Update Software, 1996. Updated quarterly. Available from: BMJ Publishing Group, London.

5 Gilbert R. The changing epidemiology of SIDS. Arch Dis Child 1994;70:445-9.

6 Fielder AR, Quinn GE. Evidently, evidence-based. $\mathrm{Br} \mathcal{f}$ Ophthalmol 1996;80:273-4.

Grimshaw JM, Russell I. Effect of clinical guidelines on medical practice: a systematic review of rigourous evaluations. Lancet 1993;342:1317-22.

8 Davis DA, Thomson MA, Oxman AD, Haynes RB. Changing physician performance. A systematic review of the effect of continuing medical eduperformance. A systematic review of the effe

9 Yano EM, Fink A, Hirsch SH, Robbins AS, Rubenstein LV. Helping practices reach primary care goals: lessons from the literature. Arch Intern Med 1995;155:1146-56.

10 Hayward RSA, Wilson MC, Tunis SR, Bass EB, Guyatt G. Users guides to the medical literature. VIII How to use clinical practice guidelines. A. Are the recommendations valid? $¥ A M A$ 1995;274:570-4

11 Grimshaw J, Eccles M, Russell I. Developing clinically valid practice guidelines. Fournal of Evaluation and Clinical Practice 1995;1:37-48.

12 Fahey TP, Peters TJ. What constitutes controlled hypertension? Patien based comparison of hypertension guidelines. $B M \mathcal{F}$ 1996;313:93-6.

13 Mittman BS, Tonesk X, Jacobsen PD. Implementing clinical practice guidelines: social influence strategies and practitioner behaviour change. Quality Review Bulletin 1992;18:413-22.

14 Joint Working Party: Royal College of Ophthalmologists, British Association of Perinatal Medicine. Retinopathy of prematurity: guidelines for screening and of Perinatal Medicine. Retinopathy of prematurity: guidelines for

15 treatment. London: Royal Colege of Ophthalmologists, 1995. and costs or health care. Lancet 1996:347:595-8.

16 Freemantle N, Long A, Mason J, et al. The treatment of persistent glue ear in children. Effective health care. Leeds: School of Public Health, 1992: 4 .

17 Eddy DM. Clinical decision making: from theory to practice. Anatomy of decision. $\mathscr{F} A M A$ 1990;263:441-3

18 Dowie J. The research-practice gap and the role of decision analysis in closing it. Health Care Analysis 1966;4:1-14.

19 Sackett DL, Rosenberg WMC, Gray JA, Haynes RB, Richardson WS. Evidence-based medicine: what it is and what it isn't. BMf 1996;312:71-2.

20 Klassen TP, Feldman ME, Watters LK, Sutcliffe T, Rowe PC. Nebulized budesonide for children with mild to moderate croup. $N$ Engl $\mathcal{f}$ Med 1994: 331:285-9.

21 Richardson WS, Wilson MC, Nishikawa J, Hayward RSA. The well built clinical question: a key to evidence-based decisions. ACP fournal Club 1995:A12-3.

22 Oxman AD, Sackett DL, Guyatt G. Users' guides to the medical literature. I. How to get started. $\mathcal{F} A M A$ 1993;270:2093-5.

23 Guyatt G, Sackett DL, Cook DJ. Users' guides to the medical literature. II. How to use an article about therapy or prevention. A. Are the results of the How to use an article about therapy or prev

24 Guyatt G, Sackett DL, Cook DJ. Users' guides to the medical literature. II. How to use an article about therapy or prevention. $B$. What were the results and will they help me in caring for my patients? $f A M A$ 1993;271:59-63.

25 Jaeschke $R$, Guyatt $G$, Sackett DL Users' guides to the medical literature. III. How to use an article about a diagnostic test. A. Are the results of the III. How to use an article about a diagn valid? $¥ A M A$ 1994;271:389-91.

26 Jaeschke R, Guyatt G, Sackett DL. Users' guides to the medical literature. III How to use an article about a diagnostic test. B. What were the results and will they help me in caring for my patients? $\mathfrak{f} A M A$ 1994;271:703-7. 
27 Levine M, Walter S, Lee H, Haines T, Holbrook A, Moyer V. Users' guides to the medical literature. IV. How to use an article about harm. $\mathcal{f} A M A$ 1994;271:1615-9.

28 Laupacis A, Welss G, Richardson WS, Tugwell P. Users' guides to the medical literature. V. How to use an article about prognosis. $\mathscr{f} A M A$ cal literature.

29 Oxman AD, Cook DJ, Guyatt G. Users' guides to the medical literature. VI. How to use an overview. $\mathscr{F} A M A$ 1994;272:1367-71.

30 Husby S, Agertoft L, Mortensen S, Pedersen S. Treatment of croup with nebulised steroid (budesonide): a double blind, placebo controlled study. Arch Dis Child 1992;68:352-5.

31 Geelhoed GC, MacDonald WBG. Oral and inhaled steroids in croup: a randomised, placebo controlled trial. Pediatr Pulmonol 1995;20:355-61.

32 Haines A, Jones R. Implementing findings of research. $B M \mathcal{F}$ 1994;308:1488-92

33 Kairys SW, Marsh Olmstead E, O'Connor GT. Steroid treatment of laryngotracheitis: a meta-analysis of the evidence from randomized trials. Pediatrics 1989;83:683-93.

34 Waring GO. Evaluating new refractive surgical procedures: free market madness versus regulatory rigor mortis. $\mathcal{f}$ Refract Surg 1995;11:335-9.

35 Dawes RM, Faust D, Meehl PE. Clinical versus actuarial judgement. Science 1989;243:1668-74.
36 McKibbon KA, Walker-Dilks CJ. Beyond ACP Journal Club: how to harness MEDLINE for therapy problems. ACP fournal Club 1994;121: A10-2.

37 McKibbon KA, Walker-Dilks CJ. Beyond ACP Journal Club: how to harness MEDLINE for diagnostic problems. ACP fournal Club 1994;121: A10-2.

38 McKibbon KA, Walker-Dilks CJ, Haynes RB. Beyond ACP Journal Club: how to harness MEDLNNE for etiology problems. ACP fournal Club 1994; 121:A10-2.

39 McKibbon KA, Walker-Dilks CJ, Haynes RB, Wilczynski N. Beyond ACP Journal Club: how to harness MEDLINE for prognosis problems. ACP fournal Club 1994;123:A12-4.

40 Sackett DL Haynes RB. On the need for evidence-based medicine. Evidence-Based Medicine 1995;1:5-6.

41 Bennett RJ, Sackett DL, Haynes RB, Neufeld VR. A controlled trial of teaching critical appraisal of the clinical literature to medical students. $\mathfrak{f A M A} 1987 ; 257: 2451-4$.

42 Shin JH, Flaynes RB, Johnston ME. Effect of problem-based, self-directed undergraduate education on life-long learning. Can Med Assoc F 1993;148: 969-76.

\section{Integrated management of childhood infections and malnutrition: a global initiative}

\section{Global childhood mortality}

Twelve million children die each year before they reach their fifth birthday. The majority $(70 \%)$ of these deaths are due to diarrhoea, pneumonia, measles, malaria, or malnutrition - and often to a combination of these conditions. Moreover, these conditions typically account for three out of four sick children seeking care at a health facility. ${ }^{1}$

Acute respiratory infections (ARI) are the leading cause of mortality in children worldwide, causing one third of all child deaths in 1993 (approximately four million). ${ }^{2}$ Deaths from ARI are mainly due to bacterial pneumonia. ${ }^{2} 3$ Some three million diarrhoeal disease episodes in young children resulted in death in 1993, accounting for $25 \%$ of child deaths. Globally, $50 \%$ of these deaths were due to acute watery diarrhoea, $35 \%$ to persistent diarrhoea, and $15 \%$ to dysentery. Measles and malaria are estimated to be associated with $10 \%$ and $8 \%$ of childhood deaths respectively. The latest World Health Organisation (WHO) estimates state that malnutrition is associated as an underlying cause with $54 \%$ of all childhood deaths, an upward revisions from the earlier estimate of $29 \%{ }^{1}$

Low birth weight, suboptimal breast feeding practices, malnutrition, and maternal behaviour influencing child care are important risk factors associated with increased incidence and severity of these diseases. The most important environmental risk factors are indoor air pollution for pneumonia and inadequate water supply and sanitation for diarrhoeal diseases. HIV infection is an additional risk factor of growing importance. ${ }^{45}$

\section{Need for an integrated approach to the management of sick children}

Almost all developing countries have reported reductions in child mortality in the last 10 years. The United Nations estimates that 13.3 million children under 5 years of age died in the developing world in 1985, and 12.2 million died in $1993 .^{6}$ This represents a decrease from 117 deaths per 1000 live births in 1985 to 97 in 1993. Much has been learned from disease specific control programmes such as those tackling diarrhoeal disease and ARI in the past 15 years. ${ }^{78}$ However experience in developing countries with high child mortality has shown that children presenting with severe illness often have multiple disorders and dem- onstrates the need for a more comprehensive approach to the assessment and management of sick children that ensures prompt recognition of septicaemia, anaemia, malnutrition, and malaria as well as dehydration, dysentery, persistent diarrhoea, and pneumonia. The challenge is now to combine these successful approaches to ARI and diarrhoeal disease case management and extend them to include the clinical management of malaria, measles, meningitis, and malnutrition. The WHO and the Unicef have responded to this challenge and developed an approach based on the integrated management of the sick child. These efforts involve some 12 programmes within WHO and are coordinated by WHO's new Division of Child Health and Development.

\section{Developing integrated case management guidelines} Integrated guidelines for management of the sick child have been developed through a process of review of existing disease specific guidelines, systematic literature review, clinical and health systems research, and field testing. The guidelines promote an approach to clinical management that is appropriate for first level outpatient facilities such as health centres in developing countries. Diagnosis is not dependent on laboratory tests but instead is based solely on valid yet simple clinical signs which health workers from various backgrounds can be trained to recognise accurately. Experience in a number of developing countries has shown that this approach results in health workers making clinical decisions about the management of sick children that accord closely with the independent assessments of experienced paediatricians (WHO, results of Arusha field test, 1995; unpublished).$^{9-11}$ This approach combines several child health interventions. There is evidence of their effectiveness in reducing mortality from community based intervention trials (for example case management of $A R I$, vitamin $A$ administration, and measles immunisation), clinical trials (for example vitamin A treatment in measles), or from observations of decreased case fatality rates after the implementation of standardised guidelines (for example treatment of severe malaria and diarrhoeal disease). ${ }^{12-15}$

The case management guidelines that have been developed are targeted at health workers in busy health centres and outpatient departments of small hospitals. In many circumstances these will be medical assistants, para- 